\title{
A Novel Synthesis Route to Produce Boron Nitride Nanotubes for Bioapplications
}

\author{
Tiago Hilário Ferreira, Paulo Roberto Omelas da Silva, Raquel Gouvêa dos Santos, \\ Edésia Martins Barros de Sousa*
}

Nanotechnology Service, Nuclear Technology Development Center (CDTN)/CNEN, Avenda Presidente Antônio Carlos, Belo Horizonte, Brazil.

Email: *sousaem@cdtn.br

Received June 27 $7^{\text {th }}, 2011$; revised July $22^{\text {nd }}, 2011$; accepted August $12^{\text {th }}, 2011$.

\begin{abstract}
Nanostructures of boron nitride have attracted a great deal of interest due to their potential applications that comprise a broad range of topics, including biomedical technology, since it presents good chemical stability and suggests good biological inertia. This paper reports a facile and effective synthesis based on CVD process with new conditions to produce boron nitride nanotubes in higher amount using boron powder, ammonium nitrate and hematite as catalysts in tubular furnace, without using extreme conditions. The characterization of the material was carried out by Fourier transformed infrared spectroscopy (FTIR), X-ray diffraction (XRD), thermogravimetric analysis, scanning electron microscopy (SEM) and transmission electron microscopy (TEM). From the results, it was possible to verify the production of a hexagonal BN nanotube filled with Fe nanoparticles. It was possible to understand the reactions involved in synthesis process, and also confirm the formation of hexagonal boron nitride nanotubes with iron nanoparticles as catalysts. Depending on the final use, samples need to be purified to analyze their unique properties in some bioapplications. In the other hand, sometimes BNNTs containing Fe nanoparticles have potential for use in therapeutic drug, gene and radionuclide delivery, and radio frequency methods for the catabolism of tumors via hyperthermia. In this sense, some application-related studies on BNNTs such as biocompatibility tests have also been investigated in both pure and BN nanotube filled with Fe.
\end{abstract}

Keywords: Boron nitride, Nanotubes, Biocompatibility Testing, Bioapplications

\section{Introduction}

In the last decade, significant research efforts have been devoted to achieve materials with well-defined nanostructures for wide range of applications [1,2]. Nanotubes materials are currently a field of intensive activity due to their high potential in a very broad range of applications due to their outstanding mechanical, electronic, optical, and thermal properties, and in particular, their high aspect ratio and propensity to functional modification for biomedical applications.

After the discovery of carbon nanotubes (CNT) it has been suggested that carbon is not a unique material being able to form nanotubes. In this sense, boron nitride appears as a potential material for this class in view of the structural similarity of graphite and bulk BN [3].

Hexagonal boron nitride (h-BN) is well known as one important ceramic material with outstanding thermal and electrical properties. Furthermore it has excellent chemical stability, good resistance to corrosion, low density and high melting point [4]. These characteristics make h-BN an attractive candidate for a wide range of technical applications $[5,6]$. In the field of biomedical technology its use as nanostructured materials has been proposed due to its unique properties that suggest a good biological inertia.

Nowadays, there is a fast growth of the number of studies on boron nitride nanotubes, BNNT, aiming at, among other aspects i) the investigation of the synthesis parameters [7], ii) characterization of the physical property in general [8], iii) evaluation and improvement of the stability by introducing other compounds [9], iv) surface modification [10], and v) biological behaviors [11].

Regarding to the synthesis parameters, since the discovery of CNTs [12], research into new and improved BNNT synthetic techniques has been towards enhance yield, obtain better nanostructure quality, and controlled chirality and diameter. Recently, many studies have been reporting the preparation of nanostructures of boron ni- 
tride with special morphologies, such as nanotubes [13], nanocapsules [14], nanocages [15], porous structures [16] and hollow spheres [17]. Traditionally, h-BN was prepared by the classical high-temperature synthesis routes, including reaction of $\mathrm{B}_{2} \mathrm{O}_{3}$, boric acid, or borax with carbon and nitrogen/ammonia and urea at temperature around $2000^{\circ} \mathrm{C}$ [18]. On the other hand, for special BN nanostructures synthesis, laser ablation, chemical vaporphase, carbothermal reduction of $\mathrm{B}_{2} \mathrm{O}_{3}$ and $\mathrm{B}_{4} \mathrm{C}$ and other methods have been developed [19]. Most of these methods cannot meet the need of high yields, and therefore, the understanding on its synthesis is still a challenging subject. Moreover, BNNT obtained from different synthetic methods has different physical properties. The quality, quantity, and type of nanotubes synthesized depend on the synthetic method used.

Depending of the synthesis route, the growth of BNNTs often requires the assistance of metal catalysts, predominantly, iron group metals $\mathrm{Fe}, \mathrm{Co}$, and Ni. However, similar to the case of CNTs, the as-synthesized BNNTs often contain impurities such as metal catalyst particles or boron oxide layers on the nanotube surfaces, which need to be removed, depending on the final use. When associated with metallic nanoparticles that have magnetic properties, BNNT obey Coulomb's law and can be manipulated by an external magnetic field. Therefore it may act as a modulator of the microvascular tone. This regulation is manifested primarily in the smaller resistance arterioles, resulting in substantial modulation of microvascular flow resistance [20]. Moreover, these nanoparticles also can be coated with biological molecules to make them interact or bind to a specific target. Therefore, they have potential for use in therapeutic drug, gene and radionuclide delivery, radio frequency methods for the catabolism of tumors via hyperthermia, and contrast enhancement agents for magnetic resonance imaging applications [21].

The biocompatibility and bio-applications of inorganic nanomaterials have become hot topics in recent years. Ciofani et al. [22] initiated the first biocompatibility tests on BNNTs. In their experiments, PEI-coated BNNTs were used for in vitro tests on a human neuroblastoma cell line. The results indicated very good cell viability up to a concentration of $5.0 \mathrm{mg} / \mathrm{ml}$ of BNNTs in the cell culture medium. Chunyi Zhi et al. [23] presented an overview of the up-to-date developments in boron nitride nanotubes, including biocompatibility and bioapplications. According to them, due to natural complexity of nanomaterials, frequently, the discrepancies in results are obtained during different experiments on the same kind of nanomaterial. Therefore, we agree with them that more experiments should be performed on BNNTs with different preparation histories to confirm their intrinsic properties.
Considering the special properties of BNNT useful for various structural and biomedical applications due to the presence of small $\mathrm{Fe}$ particles as production residuals, we have explored in this work a special and facile synthesis route to obtain nanostructures of boron nitride with remarkable yield. Indeed, we investigated previously the cytotoxicity of both samples (as-prepared and containing Fe-nanoparticles) by hemolytic tests and MTT assays for pure BNNT. To accomplish this purpose, hematite nanoparticles, boron powder and ammonium nitrate were mixed and BNNT were formed by using an annealing method. The structural properties of the samples have been investigated using different techniques. The results indicate that both pure and Fe-BNNT is a potential nanomaterial for bioapplications.

\section{Experimental}

\subsection{Synthesis}

In this study, BN nanostructures samples were prepared using amorphous boron powder, ammonium nitrate $\left(\mathrm{NH}_{4} \mathrm{NO}_{3}\right)$ of a purity of $95 \%$ or better and hematite $\left(\mathrm{Fe}_{2} \mathrm{O}_{3}\right)$ of a purity of $95 \%$ and particle size less than 50 $\mathrm{nm}$. The powders were mixed well in a weight ratio of 15:15:1, respectively. An alumina boat containing the powder mixture was placed in tubular furnace and heated up to $550^{\circ} \mathrm{C}$ without gas flow. This temperature was kept constant for one hour. After that, the temperature was slowly raised until $1300^{\circ} \mathrm{C}$ in a nitrogen gas flow. Nitrogen pressure was $0.2 \mathrm{~Pa}$, and its gas flow was $50 \mathrm{sccm}$. After one hour in this temperature ammonia gas flow was introduced for one hour followed by nitrogen gas flow until the complete cooling.

The presence of impurities such as metal catalyst particles can be interesting or not, depending on the application. If the magnetic properties is essential for the proposed final use, like drug targeting or hyperthermia, these nanoparticles exert great influence on the performance of the BNNT. However, sometimes they need to be removed to enable the better application and exploiting the properties of this material. The metal particles can be found scattered or in the form of small clusters. Considering these ambiguous behavior, both as prepared and purified samples were investigated in this work. So, to purify BN nanotubes it was chosen the chemically modified techniques described in the literature [24]. The purification was based on washing the sample with $\mathrm{HCl}$ solution $(3 \mathrm{M})$ at $90^{\circ} \mathrm{C}$ for 10 minutes, and then the sample was collected by filtration and dried at $40^{\circ} \mathrm{C}$.

\subsection{Characterization}

Samples as prepared and purified were characterized by Fourier-transform infrared spectroscopy (FTIR), X-ray diffraction (XRD), thermogravimetric analysis (TGA), 
scanning electron microscopy (SEM), and transmission electron microscopy (TEM). The XRD patterns were obtained using a Rigaku Geigerflex-3034 diffractometer with a $\mathrm{Cu}-\mathrm{K} \alpha$ tube. FTIR measurements were conducted in a Perkin-Elmer 1760-X spectrophotometer in the range $4000-400 \mathrm{~cm}^{-1}$ at room temperature using $\mathrm{KBr}$ pellets. TGA measurements were performed by Shimadzu TGA $50 \mathrm{WS}$ with temperature ranging from $25^{\circ} \mathrm{C}$ to $900^{\circ} \mathrm{C}$. Approximately $3.0 \mathrm{mg}$ of start mixture and final sample were analyzed using a heating rate of $10^{\circ} \mathrm{C} \cdot \mathrm{min}^{-1}$, with nitrogen $\left(\mathrm{N}_{2}\right)$ atmosphere flow of $20 \mathrm{~mL} \cdot \mathrm{min}^{-1}$ and platinum cell open. SEM characterization was performed in a scanning electron microscope (JEOL JSM, 840A) operating at $15 \mathrm{kV}$. TEM characterization was performed through a Tecnai-G2-20-FEI 2006 electron microscope with an acceleration potential of $200 \mathrm{kV}$.

\subsection{Biocompatibility Tests}

\subsubsection{Hemolytic Tests}

For hemolytic tests, triplicates samples of as prepared and pure BNNT were prepared in suspensions of phosphate buffer solution (PBS) at concentrations of 15.0, $32.5,45,62.5,90$ and $125 \mu \mathrm{g} / \mathrm{mL}$. The samples were incubated with $300 \mu \mathrm{L}$ of blood to a final volume of $1.5 \mathrm{~mL}$ for one hour; then, the solution was centrifuged for 10 minutes to $1000 \mathrm{rpm}$, and the supernatant was read at $540 \mathrm{~nm}$ on a spectrophotometer UV-Vis (Shimadzu). PBS and Triton 5\% v/v were used as negative and positive control, respectively.

\subsubsection{Cytotoxicity Studies}

Malignant U87 (wild-type p53), T98 (mutant p53) glioblastoma, MCF-7 adenocarcinoma mammary gland cells and normal MRC-5 (diploid) fibroblast lung cells were maintained in Dulbecco's Modified Eagle's Medium (DMEM-Gibco), supplemented with $10 \%$ fetal bovine serum and antibiotics $\left(50 \mathrm{U} \cdot \mathrm{mL}^{-1}\right.$ penicillin $/ 50 \mathrm{mM}$ streptomycin), in a water jacketed incubator with atmosphere of $5 \% \mathrm{CO}_{2} / 95 \%$ air at $37^{\circ} \mathrm{C}$. The cytotoxic effects were quantified using a 3-(4,5-dimethiol-2-thioazolyl)-2, 5-diphenyl tetrazolium bromide (MTT) colorimetric assay [25]. Briefly, cells were seeded at 1500 cells/well in 96-well flat-bottomed plates and incubated for $24 \mathrm{~h}$. Cells were treated with BNNT with increasing concentrations of $0.1 ; 10.0 ; 50.0 ; 100.0 ; 200.0 \mu \mathrm{g} / \mathrm{mL}$ previously dispersed in PBS and DMEM. Following $48 \mathrm{~h}$ of incubation at $37^{\circ} \mathrm{C}$, MTT reagent was added to each well and incubated for $4 \mathrm{~h}$. After this, dimethyl sulfoxide (DMSO) was added to each well to dissolve formazan crystals and absorbance was measured at $570 \mathrm{~nm}$. All tests were performed in triplicates with full agreement between the results. The fraction of surviving cells in treated groups was calculated as a percentage of control group (incubated only in DMEM), and the absorbance in control considered $100 \%$ survival.

\section{Results and Discussion}

\subsection{Synthesis}

The knowledge of the chemical reaction mechanism is important to understand how reaction of $\alpha-\mathrm{Fe}_{2} \mathrm{O}_{3}$ with $\mathrm{B}$ proceeds to formation of the $\mathrm{BN}$ nanotubes. They can be described in Equations. (1) and (2):

$$
\begin{gathered}
10 \mathrm{~B}(\mathrm{~s})+2 \mathrm{NH}_{4} \mathrm{NO}_{3}(\mathrm{~s})+\mathrm{Fe}_{2} \mathrm{O}_{3}(\mathrm{~s}) \rightarrow \\
4 \mathrm{BN}(\mathrm{s})+3 \mathrm{~B}_{2} \mathrm{O}_{3}(\mathrm{~g})+4 \mathrm{H}_{2}(\mathrm{~g})+2 \mathrm{Fe}(\mathrm{s}) \\
3 \mathrm{~B}_{2} \mathrm{O}_{3}(\mathrm{~g})+6 \mathrm{NH}_{3}(\mathrm{~g}) \rightarrow 6 \mathrm{BN}(\mathrm{s})+9 \mathrm{H}_{2} \mathrm{O}(\mathrm{g})
\end{gathered}
$$

During the reaction process, $\mathrm{NH}_{4} \mathrm{NO}_{3}$ was decomposed into $\mathrm{NH}_{3}$ and $\mathrm{HNO}_{3}$ at low temperature. $\mathrm{NH}_{3}$ dissociated into active nitrogen vapor and $\mathrm{H}_{2}$ gas at high temperature. At the same time, $\mathrm{B}$ vapor were formed and reacted with $\mathrm{Fe}_{2} \mathrm{O}_{3}$ to produce metallic $\mathrm{Fe}$ and $\mathrm{B}_{2} \mathrm{O}_{3}$. So, the vapor is likely to contain boron oxide phases generated from the reaction of boron with $\mathrm{Fe}_{2} \mathrm{O}_{3}$. After that, Fe-filled boron nitride nanotubes began to grow on the surface of metal catalyst, as described in Equation (1). However, the proposed conditions do not favor the consumption of all boron from the reaction mixture. To complete this, the presence of an ammonia flow directs the reaction to formation of boron nitride remains, according to Equation (2).

Figure 1 shows the FTIR spectra of samples treated at 550 and $1300^{\circ} \mathrm{C}$. The presence of the band centered at $540 \mathrm{~cm}^{-1}$ which corresponds to strain on the O-B-O, and the bands centered at 760 and $1190 \mathrm{~cm}^{-1}$ related to B-O strain, indicating the presence of boron oxide $\left(\mathrm{B}_{2} \mathrm{O}_{3}\right.$ and $\mathrm{B}_{2} \mathrm{O}$ ) can be observed for the samples heated at low temperature. We also observed the presence of a small band centered at $640 \mathrm{~cm}^{-1}$ which can be ascribed to the vibration of $\mathrm{Fe}-\mathrm{O}$ bond, which is typical of hematite phase $\left(\mathrm{Fe}_{2} \mathrm{O}_{3}\right)$.

The sample treated at $1300^{\circ} \mathrm{C}$ presented characteristic bands of B-N. The most important feature displayed in the spectra is the strong asymmetric band centered at $1380 \mathrm{~cm}^{-1}$, which corresponds to the bond B-N stretch, along with a less intense band at $790 \mathrm{~cm}^{-1}$ ascribed to $\mathrm{B}-\mathrm{N}-\mathrm{B}$ bond. It is noteworthy that this technique provides important data to characterize the phase h-BN, since it is possible to distinguish $\mathrm{sp}^{2}$ bonds of hexagonal $\mathrm{h}$-BN phase samples and $\mathrm{sp}^{3}$ of cubic phase c-BN. According to Hao and colleagues [26] bonds $\mathrm{sp}^{2}$-type of $\mathrm{h}$-BN are thermodynamically stable under the synthesis conditions of this work, while for the formation of $\mathrm{sp}^{3}$ bonds typical of c-BN, there is a kinetics barrier of formation. Other authors have presented similar results in 


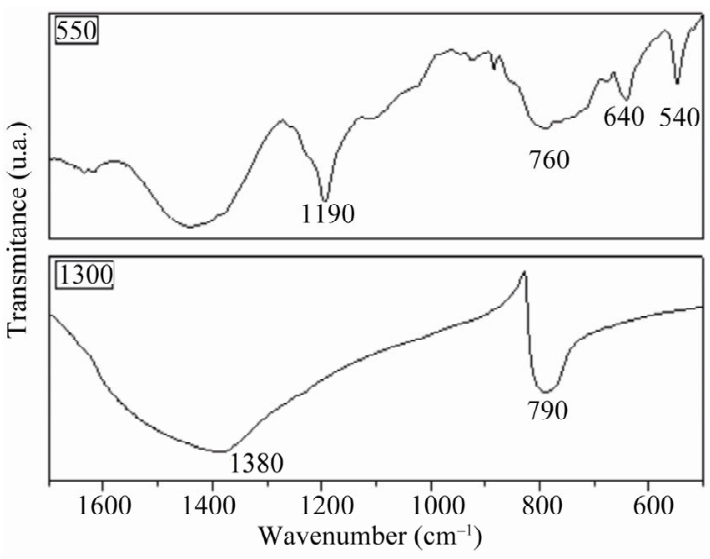

(a)

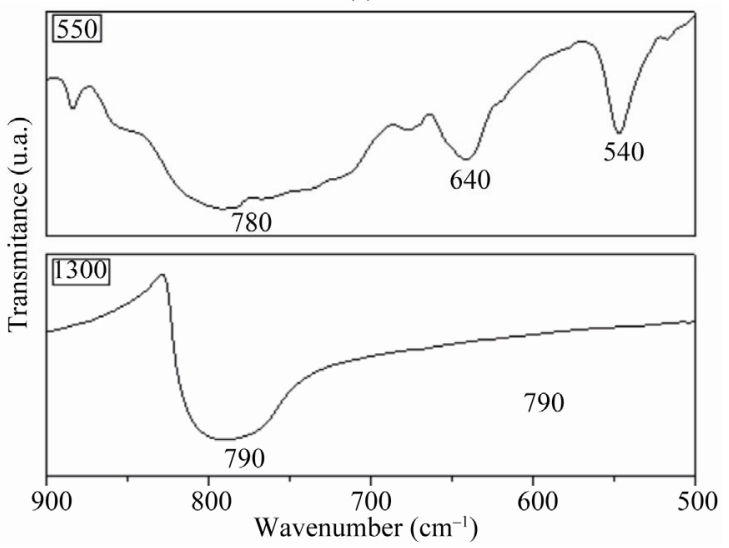

(b)

Figure 1. (a) Infrared spectrum of the samples treated at 550 and $1300^{\circ} \mathrm{C}$; (b) Expanded infrared spectrum.

which the formation of h-BN occur around $1380^{\circ} \mathrm{C}[27$, 28]. Peaks in 1096 and $1166 \mathrm{~cm}^{-1}$ are due to the formation of c-BN phase and they were not found in the sample treated at $1300^{\circ} \mathrm{C}$.

Figure 2 shows the XRD patterns of the samples treated at $550^{\circ} \mathrm{C}$ and $1300^{\circ} \mathrm{C}$. The peaks at $2 \theta=14.55^{\circ}$, $2 \theta=27.76^{\circ}, 2 \theta=30.59^{\circ}$ and $2 \theta=57.55^{\circ}$ are relative to the boron oxide $\left(\mathrm{B}_{2} \mathrm{O}_{3}\right)\left(\mathrm{JCPDS}, \mathrm{N}^{\circ} .41-624\right)$ present in curves of samples treated at $550^{\circ} \mathrm{C}$. The predominance of the boron oxides phases at this temperature suggests that the oxygen present in the initial mixture, derived from the $\mathrm{Fe}_{2} \mathrm{O}_{3}$ and from the environment, favors initially the formation of $\mathrm{B}_{2} \mathrm{O}$ (intermediate compound), and after $\mathrm{B}_{2} \mathrm{O}_{3}$. The formation of boron oxide $\left(\mathrm{B}_{2} \mathrm{O}_{3}\right)$ is of great importance in this chemical process because it is the precursor for the synthesis of h-BN. It is known that the $\mathrm{B}_{2} \mathrm{O}_{3}$ has a low vapor pressure compared to elemental boron [29] and this allows the presence of boron in a gaseous form at a lower temperature, in these synthesis conditions. In the sample treated at $1300^{\circ} \mathrm{C}$ is possible to identify the presence of typical peaks of h-BN at $2 \theta=$ $26.75^{\circ}, 2 \theta=41.58^{\circ}, 2 \theta=50.16^{\circ}$ and $2 \theta=75.86^{\circ}$

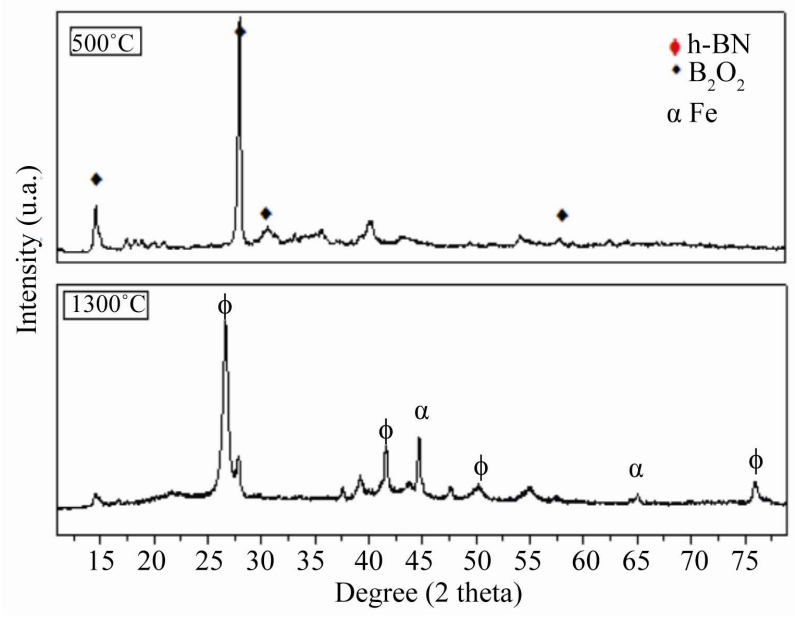

Figure 2. XRD pattern of the samples treated at 550 and $1300^{\circ} \mathrm{C}$.

(JCPDS, $\mathrm{N}^{\circ} .9$ - 12). Peaks for metallic iron and some peaks with very low intensity relative to the boron oxide $\mathrm{B}_{2} \mathrm{O}_{3}$ also can be identified. In addition, the presence of this paramagnetic iron phase was supported by Mossbauer spectroscopy at room temperature (not showed here). No noticeable peaks of other impurities, such as $\mathrm{Fe}_{2} \mathrm{O}_{3}$, were detected in this pattern. This indicates that the catalyst particles inside the $\mathrm{BN}$ nanotubes are $\alpha$-Fe metal particles.

The TGA curve of sample weight changes as a function of heating temperature is shown in Figure 3. A comparison between reaction mixture and final sample was achieved and shows distinct behavior between them. It is possible to observe a significant mass loss of starting sample which initiate at $125^{\circ} \mathrm{C}$ and is accentuated between $205^{\circ} \mathrm{C}$ and $250^{\circ} \mathrm{C}$. This mass loss of about $58 \%$ can be attributed to the presence of humidity and mainly to the decomposition of ammonium nitrate. A significant sample weight increase of about $40 \%$ between $500^{\circ} \mathrm{C}$ and $900^{\circ} \mathrm{C}$ can be observed, and it can be explained by the formation of h-BN from the nitrogen gas flow and boron in the sample that has not reacted, according to Equations (1) and (2). For the final sample, which has been treated at $1300^{\circ} \mathrm{C}$ the curve presented a small mass loss (approximately 3\%), showing a very good thermal stability of the final h-BN material. Both XRD and FTIR analyses suggest that the weigh increase corresponds to the h-BN formation confirming the analysis from TGA.

Figure 4 shows the micrograph of the sample treated at $1300^{\circ} \mathrm{C}$ obtained by SEM using backscattered electron beam (Figure 4(a)), where it is possible to observe a few sheets of h-BN in nano-scale, and the indication of initial formation of BNNTs. It is also possible to observe the presence of iron nanoparticles (bright points) between $\mathrm{BN}$ sheets, and they are found throughout the sample. 


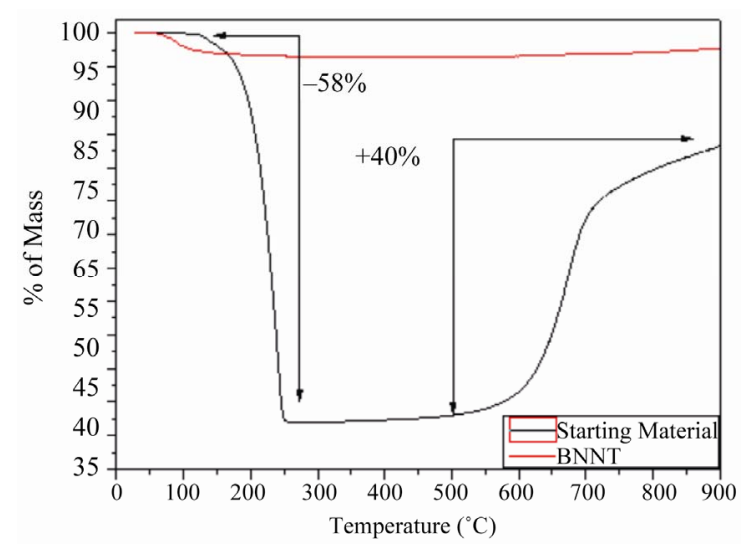

Figure 3. Thermogravimetric analysis of starting material and sample obtained after heat treatment.

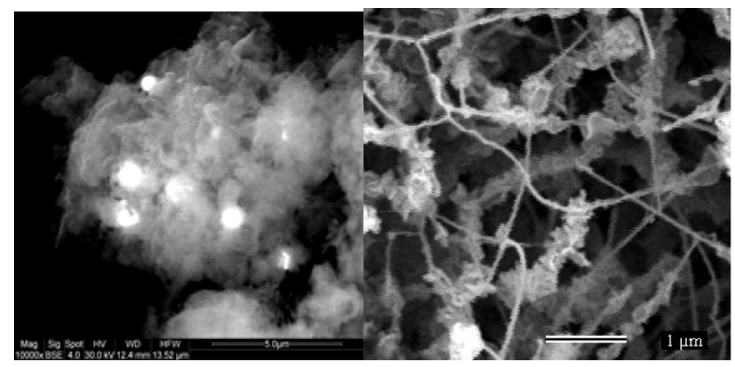

Figure 4. SEM micrographs of (a) BN nanostructure with iron nanoparticle and (b) boron nitride nanotubes.

Figure 4(b) shows the presence of nanotubes and nanofibers with about $100 \mathrm{~nm}$ of diameter. The TEM images of the sample are shown in Figure 5. It could be seen BN sheets and some nanotubes like observed by SEM images (Figure 4). From expanded scale (Figure 5(b)) it was possible to observe interplanar spaces of h-BN when the sample is positioned in the perpendicular direction to the electron beam of the transmission microscope.

The starting BN nanotubes samples contain catalyst particles including $\mathrm{Fe}$ and a small amount of $\mathrm{B}_{2} \mathrm{O}_{3}$, as determined FTIR and DRX. After this treatment, a selective chemical leaching process was used to remove metal catalysts from $\mathrm{BN}$ nanotubes. Hydrochloric acid $(\mathrm{HCl})$ was found as an effective acid that could dissolve both Fe and boron oxide. Regarding to purification process, the following reactions occurred during the leaching process:

$$
\mathrm{Fe}+\mathrm{HCl} \rightarrow \mathrm{FeCl}_{3}+\mathrm{H}_{2}
$$

The product $\mathrm{FeCl}_{3}$ and the residual $\mathrm{B}_{2} \mathrm{O}_{3}$ are soluble in hot water and they can be easily removed by washing with hot water followed by filtration, according to used method. XRD analysis (Figure 6) confirmed the effective chemical leaching process. The Fe diffraction peak is absent from the XRD pattern taken from the leached sample. The unchanged BN diffraction peaks suggest

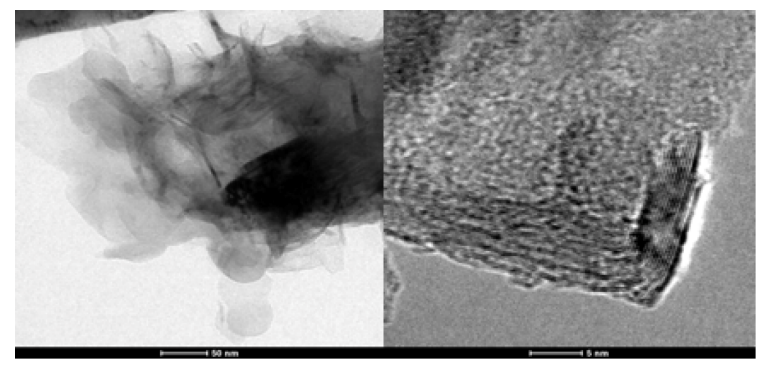

Figure 5. TEM images of the BN nanostructures.

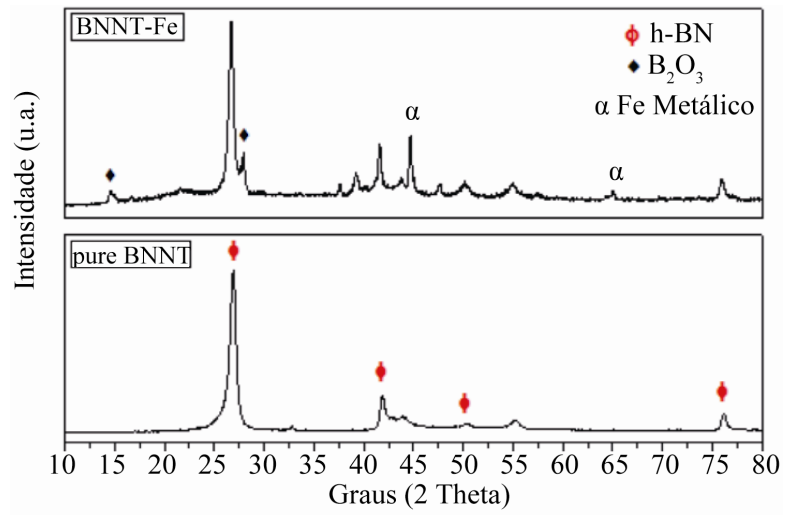

Figure 6. XRD pattern of the samples with iron and after purification.

that BNNT structures are not damaged by the above treatment. From the results obtained by the characterization of samples, it was observed that the hexagonal boron nitride was successfully achieved in satisfactory quantity. However, the synthesis parameters of the proposed synthesis lead to a partially formation of BN nanotubes, as can be confirmed by the results of SEM and TEM characterization. In this context, it was proposed a second heat treatment at a lower temperature in a nitrogen gas flow during one hour, around $900^{\circ} \mathrm{C}$, to promote the formation of nanotubes. Samples after this second heat treatment were analyzed by TEM.

In Figure 7 TEM images of BNNTs clearly evidence a straight-walled tubular structure having an outer diameter of approximately $30 \mathrm{~nm}$ (Figure 7(a)). Furthermore, the HRTEM image (Figure 7(b)) reveals the multiwalled nature of the BNNTs with each layer being clearly distinguishable; the layers are spaced by $0.33 \mathrm{~nm}$ and it corresponds to the crystallographic plane 002. This distance of the BN layers agrees with that established by Terrones and colleagues [13], and indicates that our BN nanotube has a similar structure with those products synthesized by arc discharge and laser ablation techniques.

From the analysis of Figure $\mathbf{8}$ it is possible to observe the ordering of the layers of h-BN (top of the figure and in highlighted frame) with interplanar space of $0.18 \mathrm{~nm}$. 


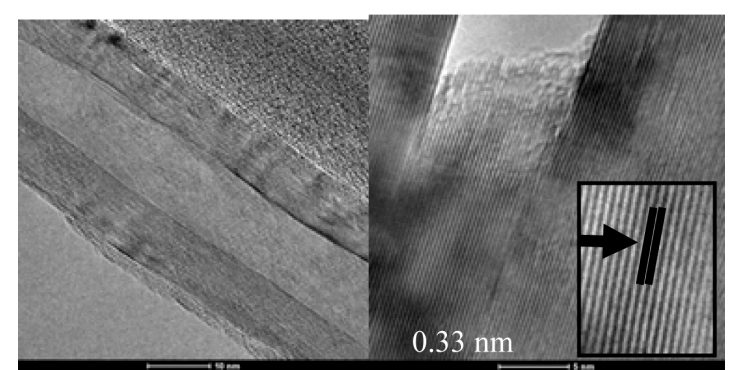

Figure 7. High-resolution TEM images of individual BN nanotubes and of crystallographic plane 002.

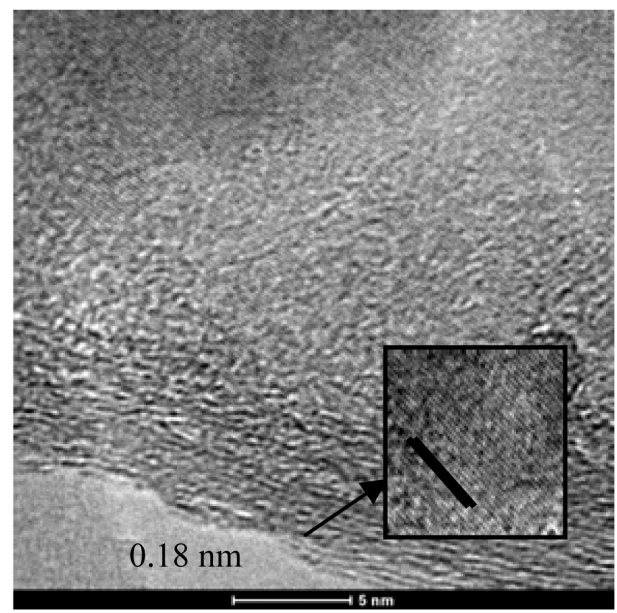

Figure 8. TEM image of crystallographic plane 102.

This value (d) corresponds to the peak at $2 \theta=41.58^{\circ}$ obtained in the analysis by XRD, which is characteristic of h-BN. According to the database JCPDS $\mathrm{N}^{\circ} 9-12$, this peak corresponds to the crystallographic plane 102. This plan is extremely difficult to visualize and it had not commonly reported.

\subsection{Bioaplications}

The data analysis from hemolytic test show that the percentage of hemolysis tended to zero for all concentrations evaluated, according to Figures 9 and 10. These results suggest that the as prepared BNNT and pure materials tested have no significant hemolytic activity, indicating a good biotolerance to the materials.

The results of the MTT assay, as a measure of metabolic activity of different cells following $48 \mathrm{~h}$ of contact with the pure BNNT are shown in Figures 11 and 12. The cytotoxicity of BNNT nanoparticles increased slightly with increasing mass concentration of particle in all of the cell cultures. Although the inhibitory concentration of BNNT that kills 50\% (IC50) of normal cells is around $50 \mu \mathrm{g} / \mathrm{mL}$, only from a concentration of $200 \mu \mathrm{g} / \mathrm{mL}$ of BNNT nanoparticles, the cell viability decreased to a level between $40 \%$ and $50 \%$ of control. Similar results

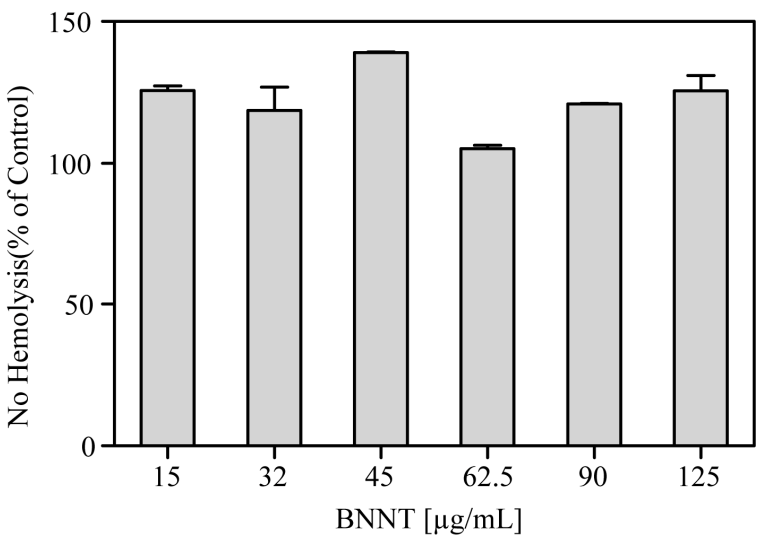

Figure 9. Study of the Hemolytic activities of pure BNNT in concentrations ranging 15 - $125 \mu \mathrm{g} / \mathrm{mL}$ compared to negative control (PBS). The results showed no hemolytic activity in all the concentrations analyzed.

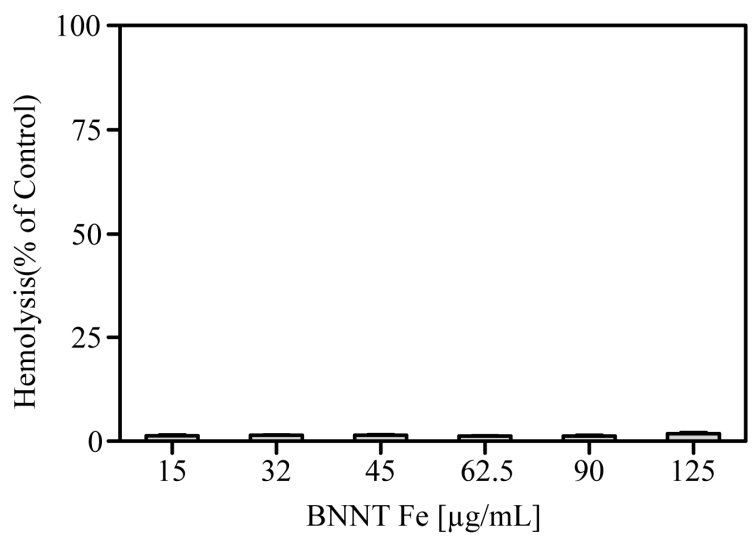

Figure 10. Study of the Hemolytic activities of pure BNNT Fe in concentrations ranging $15-125 \mu \mathrm{g} / \mathrm{mL}$ compared to positive control (TRITON). The results showed no hemolytic activity significative in all the concentrations analyzed.

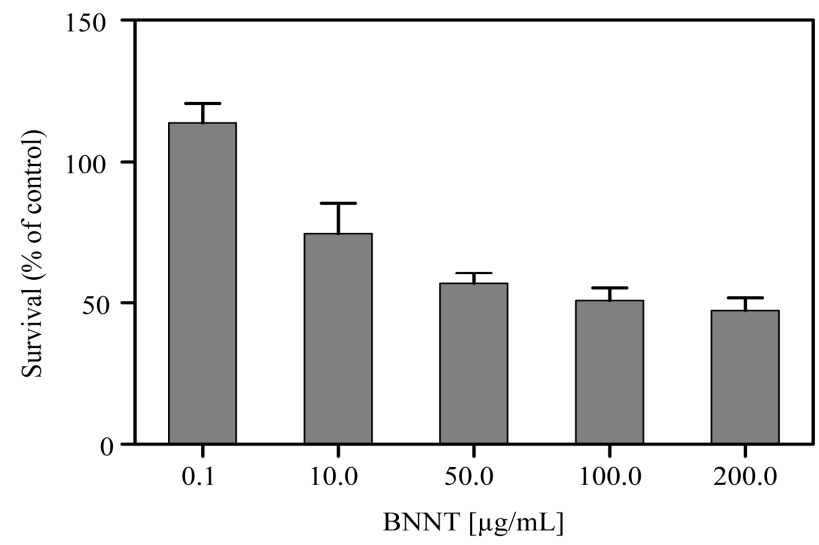

Figure 11. Effect of boron nitride nanocomposite (BNNT) in concentrations ranging from 0.1 to $200.0 \mu \mathrm{g} / \mathrm{mL}$ on normal cell lines (MRC-5) after $48 \mathrm{~h}$ treatment. The inhibitory concentration of BNNT that kills $50 \%$ (IC50) of normal cells is around $50 \mu \mathrm{g} / \mathrm{mL}$. 


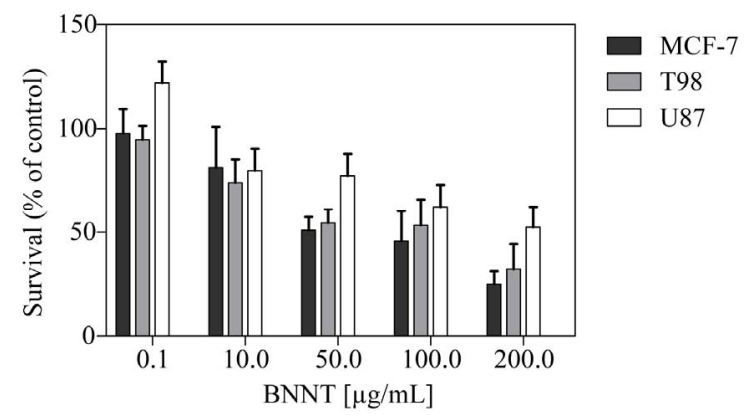

Figure 12. Effect of boron nitride nanocomposite (BNNT) in concentrations ranging from 0.1 to $200.0 \mu \mathrm{g} / \mathrm{mL}$ in different tumor cells lines MCF-7, T98 and U87 after $48 \mathrm{~h}$ treatment by the MTT assay. The inhibitory concentration of BNNT that kills $50 \%$ (IC50) of normal cells is around $50 \mu \mathrm{g} / \mathrm{mL}$.

were found for tumor cells lines. However, the results revealed that BNNT may have important toxicicity at concentrations higher than $200 \mu \mathrm{g} / \mathrm{mL}$.

To our knowledge there are very few studies directly or indirectly investigating the toxic effects of boron nitride nanomaterials and no clear guidelines are presently available to quantify these effects [30,31]. As when one thinks in bioapplication, the material may be in contact with cells or biological fluids such as blood. Evaluation of the biocompatibility of BNNT on normal fibroblast cells shows that the IC50 of the evaluated BN's is around $50 \mu \mathrm{g} / \mathrm{mL}$. According Hussain et al. [32], the nanomaterials cadmium oxide (CdO-1000 $\mathrm{nm})$ and silver (Ag-15 and $100 \mathrm{~nm}$ ) showed high toxicity for rat liver derived cell line (BRL 3A) using this same method. Concentration as low as $25 \mu \mathrm{g} / \mathrm{ml}$ of CdO-1000 nm and $50 \mu \mathrm{g} / \mathrm{ml}$ of Ag-15 and $100 \mathrm{~nm}$ were able to evoke around $95 \%$ of cell death indicating that the IC50 for these materials, a parameter of toxic potential, is lower than 25 and $50 \mu \mathrm{g} / \mathrm{mL}$, respectively. Based in our study, the IC50 of the evaluated BNNT (50 nm) on MRC-5 (fibroblast lung human) and tumor cell lines was higher than $200 \mu \mathrm{g} / \mathrm{mL}$, indicating that $\mathrm{BN}$ are less toxic than CdO-1000, Ag-15 and Ag-100. These data show that BNNT exhibited a good biocompatibility at concentrations adequate for potential pharmacological applications (between 0.1 to $10 \mu \mathrm{g} / \mathrm{mL}$ ). Indeed, according to the literature, boron nitride nanotubes are suitable for the development of novel nanovectors for cell therapy, drug delivery system, and other biomedical applications [11].

In conclusion, the MTT assay revealed that BNNT may become lightly toxic to cultured human cells at high concentrations. Although important, these results are preliminary and a deeper study of performance of these materials has to be developed.

\section{Conclusions}

Summarizing, we developed an easy and direct chemis- try synthesis route to obtain nanotubes of boron nitride with iron nanoparticles, without use of extreme conditions. From FTIR and XRD analysis it was possible to understand the reactions involved in the synthesis process, and also to confirm the formation of hexagonal boron nitride. From SEM and TEM images, it was possible to observe the formation of $\mathrm{BN}$ nanotubes and also the crystallographic planes 002 and 102. Preliminary biocompatibility tests revealed that hemolytic activity of this material is extremely low. MTT tests show that BNNT exhibited a good biocompatibility at concentrations adequate for potential pharmacological applications. The features presented suggest that this nanomaterial can be used for some biological applications, as nanovectors for cell therapy, drug delivery system and to assist in cancer treatment by using radioisotopes.

\section{Acknowledgements}

This research was supported by the Brazilian agencies CAPES, CNPq and FAPEMIG. The authors would like to thank the Microscopy Center-UFMG for technical support during electron microscopy work.

\section{REFERENCES}

[1] T. Tsoncheva, J. Rosenholm, C. V. Teixeira, M. Dimitrov, M. Linden and C. Minchev, "Preparation, Characterization and Catalytic Behavior in Methanol Decomposition of Nanosized Iron Oxide Particles within Large Pore Ordered Mesoporous Silicas," Microporous and Mesoporous Materials, Vol. 89, No. 1-3, 2006, pp. 209-218. doi:10.1016/j.micromeso.2005.10.028

[2] A. Sousa and E. M. B. Sousa, "Influence of Synthesis Temperature on the Structural Characteristics of Mesoporous Silica," Journal of Non-Crystalline Solids, Vol. 352, No. 32-35, 2006, pp. 3451-3456. doi:10.1016/j.jnoncrysol.2006.03.080

[3] M. Ishigami, S. Aloni and A. Zettl, "Properties of Boron Nitride Nanotubes," American Institute of Physics, Vol. 696, 2003, pp. 94-99.

http://scitation.aip.org/getabs/servlet/GetabsServlet?prog $=$ normal\&id=APCPCS000696000001000094000001\&idt ype $=$ cvips\& gifs $=$ yes\&ref $=$ no

[4] M. Engler, C. Lesniak, R. Damasch, B. Ruisinger and J. Eichler, "Hexagonal Boron Nitride (hBN) Applications from Metallurgy to Cosmetics," German Ceramic Society, Vol. 84, No. 12, 2007, pp. 49-53.

[5] M. W. Smith, K. C. Jordan, C. Park, W. Kim, P. T. Lillehei, R. Crook and J. S. Harrison, "Very Long Single- and Few-Walled Boron Nitride Nanotubes via the Pressurized Vapor/Condenser Method," Nanotechnology, Vol. 20, No. 50, 2009, pp. 505-604. doi:10.1088/0957-4484/20/50/505604

[6] R. T. Paine and C. K Narula, "Synthetic Routes to Boron Nitride," Chemical Reviews, Vol. 90, No. 1, 1990, pp. 73-91. doi:10.1021/cr00099a004 
[7] A. Loiseau, F. Willaime, N. Demoncy, G. Hug and H. Pascard, "Boron Nitride Nanotubes with Reduced Numbers of Layers Synthesized by Arc Discharge," Physical Review Letters, Vol. 76, No. 25, 1996, pp. 4737-4740. doi:10.1103/PhysRevLett.76.4737

[8] R. Ma, D. Golberg, Y. Bando and T. Sasaki, "Syntheses and Properties of B-C-N and BN Nanostructures," Philosophical Transactions of the Royal Society A, Vol. 362, No. 1823, 2004, pp. 2161-2186.

[9] X. Chen, P. Wu, M. Rousseas, D. Okawa, Z. Gartner, A. Zettl and C. Y. N. R. Bertozzi, "Boron Nitride Nanotubes Are Noncytotoxic and Can Be Functionalized for Interaction with Proteins and Cells," Journal of the American Chemical Society, Vol. 131, No. 3, 2009, pp. 890-891. doi:10.1021/ja807334b

[10] W. Wang, Y. Bando, C. Zhi, W. Fu, E. Wang and D. Golberg, "Aqueous Noncovalent Functionalization and Controlled Near-Surface Carbon Doping of Multiwalled Boron Nitride Nanotubes," Journal of American Chemical Society, Vol. 130, No. 26, 2008, pp. 8144-8145. doi:10.1021/ja8020878

[11] G. Ciofani, V. Raffa, A. Menciassi and A. Cuschieri, "Boron Nitride Nanotubes: An Innovative Tool for Nanomedicine," Nanotoday, Vol. 84, No. 1, 2009, pp. 8-10. doi:10.1016/j.nantod.2008.09.001

[12] S. Iijima, "Helical Microtubules of Graphitic Carbon," Nature, Vol. 354, No. 7, 1991, pp. 56-58. doi: $10.1038 / 354056 \mathrm{a} 0$

[13] M. Terrones, J. M. Romo-Herrera, E. Cruz-Silva, F. López-Urías, E. Munoz-Sandoval, J. J. Velázquez-Salazar, H. Terrones, Y. Bando and D. Golberg, "Pure and Doped Boron Nitride Nanotubes," Materials Today, Vol. 10 , No. 5, 2007, pp. 30-38. doi:10.1016/S1369-7021(07)70077-9

[14] T. Oku, M. Kuno and H. Kitahara, "Formation, Atomic Structures and Properties of Boron Nitride and Carbon Nanocage Fullerene Materials," International Journal of Inorganic Materials, Vol. 3, No. 7, 2001, pp. 597-612. doi:10.1016/S1466-6049(01)00169-6

[15] Y. Pan, K. F. Huo, Y. M. Hu, J. J. Fu, Y. N. Lu, Z. D. Dai, Z. Hu and Y. Chen, "Boron Nitride Nanocages Synthesized by a Moderate Thermochemical Approach," Small, Vol. 1, No. 2, 2005, pp. 1199-1203. doi:10.1002/smll.200500218

[16] B. Rushton and R. Mokaya, "Mesoporous Boron Nitride and Boron-Nitride-Carbon Materials from Mesoporous Silica Templates," Journal of Materials Chemistry, Vol. 18, No. 2, 2008, pp. 235-241. doi:10.1039/b713740k

[17] L. Y. Chen, Y. L. Gu, L. Shi, Z. H. Yang, J. H. Ma and Y. T. Qian, "A Room-Temperature Approach to Boron Nitride Hollow Spheres," Solid State Communication, Vol. 130, No. 8, 2004, pp. 537-540. doi:10.1016/j.ssc.2004.03.009

[18] R. S. Kalyoncu, "BN Powder Synthesis at Low Temperatures," Ceramic Engineering and Science Proceedings, Vol. 6, No. 9-10, 1985, pp. 1356-1363. doi:10.1002/9780470320297.ch18
[19] L. Gao and J. Li, "Preparation of Nanostructured Hexagonal Boron Nitride Powder," Journal of American Ceramic Society, Vol. 86, No. 11, 2003, pp. 1982-1984. doi:10.1111/j.1151-2916.2003.tb03596.x

[20] C. Morris and T. Skalak, "Static Magnetic Fields Alter Arteriolar Tone in Vivo," Bioelectromagnetics, Vol. 26, No. 1, 2005, pp. 1-9. doi:10.1002/bem.20047

[21] Q. A. Pankhurst, J. Connolly, S. K. Jones and J. Dobson, "Applications of Magnetic Nanoparticles in Biomedicine," Journal of Physics D: Applied Physics, Vol. 36, No. 13, 2003, pp. R167-R181. doi:10.1088/0022-3727/36/13/201

[22] G. Ciofani, V. Raffa, A. Menciassi and A. Cuschieri, "Cytocompatibility, Interactions, and Uptake of Polyethyleneimine-Coated Boron Nitride Nanotubes by Living Cells: Confirmation of Their Potential for Biomedical Applications," Biotechnology and Bioengineering, Vol. 101, No. 4, 2008, pp. 850-858. doi:10.1002/bit.21952

[23] C. Zhi, Y. Bando, C. Tang and D. Golberg, "Boron Nitride Nanotubes," Materials Science and Engineering $R$, Vol. 70, No. 3-6, 2010, pp. 92-111. doi:10.1016/j.mser.2010.06.004

[24] H. Chen, Y. Chen, J. Yu and J. S. Williams, "Purification of Boron Nitride Nanotubes," Chemical Physics Letters, Vol. 425, No. 4-6, 2006, pp. 315-319. doi:10.1016/j.cplett.2006.05.058

[25] R. I Freshney, "Culture of Animal Cells: A Manual of Basic Technique," 4th Edition, Wiley-Liss, Wilmington, 2000, pp. 269-283.

[26] X. Hao, M. Yub, Z. Cui, X. Xu, Q. Wang and M. Jiang, "The Effect of Temperature on the Synthesis of BN Nanocrystals," Journal of Crystal Growth, Vol. 241, No. 1-2, 2002, pp. 124-128. doi:10.1016/S0022-0248(02)01291-5

[27] J. Vilcarromero, M. N. P. Carreño and I. Pereyra, "Mechamical Properties of Boron Nitride Thin Films Obtained by RF-PECVD at Low Temperatures," Thin Solid Films, Vol. 373, No. 1-2, 2000, pp. 273-276. doi:10.1016/S0040-6090(00)01096-8

[28] S. Y. Xie, W. Wang, K. A. Shiral-Fernando, X. Wang, Y. Lin and Y. P. Sun, "Solubilization of Boron Nitride Nanotubes," Chemical Communications, No. 29, 2005, pp. 3670-3672.

http://pubs.rsc.org/en/Content/ArticleLanding/2005/CC/b $505330 \mathrm{~g}$ doi: $10.1039 / \mathrm{b} 505330 \mathrm{~g}$

[29] H. E. Çamurlu, N. Sevinç and Y. Topkaya, "Role of Boron Carbide in Carbothermic Formation of Hexagonal Boron Nitride," Journal of Materials Science, Vol. 41, No. 15, 2006, pp. 4921-4927. doi:10.1007/s10853-006-0339-6

[30] G. Ciofani, S. Danti, D. D'Alessandro, S. Moscato and A. Menciassi, "Assessing Cytotoxicity of Boron Nitride Nanotubes: Interference with the MTT Assay," Biochemical and Biophysical Research Communications, Vol. 394, No. 2, 2010, pp. 405-411. doi:10.1016/j.bbrc.2010.03.035 
[31] D. Lahiri, F. Rouzaud, T. Richard, A. K. Keshri, S. R. Bakshi, L. Kos and A. Agarwal, "Boron Nitride Nanotube Reinforced Polylactide-Polycaprolactone Copolymer Composite: Mechanical Properties and Cytocompatibility with Osteoblasts and Macrophages in Vitro," Acta Biomaterialia, Vol. 6, No. 9, 2010, pp. 3524-3533. doi:10.1016/j.actbio.2010.02.044

[32] S. M. Hussain, K. L. Hess, J. M. Gearhart, K. T. Geiss and J. J. Schlager, "In Vitro Toxicity of Nanoparticles in BRL 3A Rat Liver Cells," Toxicology in Vitro, Vol. 19, No. 7, 2005, pp. 975-983. doi:10.1016/j.tiv.2005.06.034 